\title{
Lean Six Sigma in Higher Education
}




\section{Praise for Lean Six Sigma in Higher Education}

'Higher Education institutions create true value when knowledge is being developed and transferred. Today's Higher Education institutions however comprise of many processes that are supportive to these purposes, but in itself do not create true value. This book is an excellent guide for managers and professionals in the Higher Education sector looking for process or product optimization within their institutes. It guides in separating value adding from nonvalue adding or even wasteful activities, and provides practical aids and tools for process optimization in the Higher Education sector.'

- Bart A. Lameijer, Assistant Professor and Senior Consultant, University of Amsterdam Business School, Netherlands

'The importance of a long term strategic improvement framework for Higher Education has never been more necessary than today. Many attempts have been made by external policy makers in government, or internally by career administrators. Most have failed miserably to make any improvement in efficiency or effectiveness over the past 30 years. Costs have gone up and Quality has come down. Professor Jiju Antony and his team have gone outside of Academia to study the use of principles, tools and techniques with a proven track record in Manufacturing, business and service organisations. It is shown without doubt that Lean Six Sigma in Higher Education is needed right now! The book breaks down many myths and misconceptions about Lean Six Sigma and I encourage all administrators, leaders and policy makers to give this book a chance and read it with an open mind. Lean Six Sigma is a game-changer for Higher Education... and it needs to be given an opportunity to show its power.'

-John Dennis, Chairman International Lean Six Sigma Institute, UK

'This is another piece of art for the entire Lean Six Sigma global community! Higher Education (HE) is definitely an area full of improvement opportunities and Lean Six Sigma can be a critical component to change this game. The Editor of this book has addressed this topic brilliantly by showcasing a collection of articles including a dedicated chapter on the tools and techniques of LSS relevant to Higher Education context. This is a must-read book not only for academic leaders in HE but also for all continuous improvement practitioners that aim to promote a positive impact in this area.'

-Marcelo Machado Fernandes, MF Operational Excellence, ASQ Certified Master Black Belt, Minitab Certified Trainer, Brazil 


\title{
Lean Six Sigma in Higher Education: A Practical Guide for Continuous Improvement Professionals in Higher Education
}

\author{
EDITED BY \\ PROF. JIJU ANTONY
}

Heriot-Watt University, UK

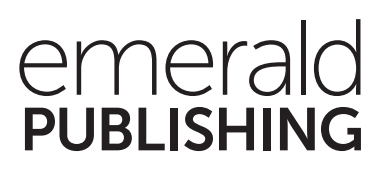

United Kingdom - North America - Japan - India - Malaysia - China 
Emerald Publishing Limited

Howard House, Wagon Lane, Bingley BD16 1WA, UK

First edition 2021

Copyright (C) 2021 Selection and Editorial matter by Jiju Antony. Published under exclusive licence.

Copyright (C) 2021 Individual chapters by their respective authors

\section{Reprints and permissions service}

Contact: permissions@emeraldinsight.com

No part of this book may be reproduced, stored in a retrieval system, transmitted in any form or by any means electronic, mechanical, photocopying, recording or otherwise without either the prior written permission of the publisher or a licence permitting restricted copying issued in the UK by The Copyright Licensing Agency and in the USA by The Copyright Clearance Center. Any opinions expressed in the chapters are those of the authors. Whilst Emerald makes every effort to ensure the quality and accuracy of its content, Emerald makes no representation implied or otherwise, as to the chapters' suitability and application and disclaims any warranties, express or implied, to their use.

\section{British Library Cataloguing in Publication Data}

A catalogue record for this book is available from the British Library

ISBN: 978-1-78769-930-4 (Print)

ISBN: 978-1-78769-929-8 (Online)

ISBN: 978-1-78769-931-1 (Epub) 
Dedicated to my wife Frenie Antony and my daughter Evelyn Antony 
This page intentionally left blank 


\section{Table of Contents}

List of Figures $x v$

List of Tables $x i x$

List of Contributors $\quad x x i$

$\begin{array}{ll}\text { Preface } & \text { xxiii }\end{array}$

Acknowledgements $x x v$

Chapter 1 An Overview of Lean Six Sigma 1

Jiju Antony, Roger Hoerl and Ronald Snee

1.1 Introduction 1

1.2 Lean Six Sigma Yesterday - The History of Lean Six Sigma 2

1.2.1 The Launch of Six Sigma 2

1.2.2 A Brief History of Lean 3

1.2.3 The Marriage of Six Sigma and Lean 4

1.2.4 Lean Six Sigma Today - The Current State of Lean Six Sigma 5

1.2.4.1 Lean Six Sigma for Public Sector

Organisations 5

1.2.4.2 Lean Six Sigma and Innovation 6

1.2.4.3 Standards for Lean Six Sigma

Certification 6

1.2.5 Future of Lean Six Sigma .... Getting Better All the Time 7

1.2.5.1 Holistic Improvement Strategy and Methodology 7

1.2.5.2 Taking Advantage of Big Data 8 
1.2.5.3 Sustaining Lean Six Sigma

1.2.5.4 Human Variation 9

1.2.6 Summary 9

References

Chapter 2 Academic Leadership - Their Culture and Characteristics

Stephen Anthony and Jiju Antony

2.1 Introduction: What Is an Academic Institution? 13

2.2 The Changing World in the Twenty-first Century 14

2.3 The Future and the Need for Leadership 15

2.4 The Characteristics and Environment These Leaders Find Themselves in 17

2.5 Academic Leadership Defined - An Authors' Perspective 20

References $\quad 21$

Chapter 3 Lean Six Sigma in Higher Education: State-of-the-Art Findings and Agenda for Future Research

Elizabeth A. Cudney and Sandy L. Furterer

3.1 Introduction 23

3.2 Methodology 24

3.2.1 Planning the Review 25

3.2.2 Conducting the Review 26

3.3 Literature Review 26

3.3.1 Six Sigma Approaches in Higher Education $\quad 26$

3.3.2 Lean Approaches in Higher Education 29

3.3.3 Lean Six Sigma Approaches in Higher

Education $\quad 32$

3.4 Analysis of the Literature 36

3.5 Summary and Future Research $\quad 37$

References $\quad 38$

Chapter 4 Challenges in the Deployment of LSS in the Higher Education Sector: Viewpoints from Leading Academics and Practitioners

Jiju Antony 
4.2 Viewpoints 43

4.3 Summary 52

Chapter 5 Readiness Factors for the Implementation and Deployment of Lean Six Sigma (or Operational Excellence) in Higher Education

Jiju Antony and Scott P. Thomson

5.1 Introduction to Readiness and Readiness Factors $\quad 53$

5.2 Readiness Factors for the Implementation and Deployment of LSS in HE 54

5.2.1 Visionary Leadership $\quad 55$

5.2.2 Management Commitment and Resources $\quad 56$

5.2.3 Focus on Customers 56

5.2.4 Linking Operational Excellence to

University's Strategy $\quad 57$

5.2.5 Organisational Culture $\quad 58$

5.2.6 Selecting the Right People 58

5.3 Managerial Implications $\quad 59$

5.4 Summary and Further Research Directions $\quad 59$

References $\quad 60$

Chapter 6 Basic Lean Six Sigma Tools for Higher Education 61

Jiju Antony and Vijaya Sunder $M$

6.1 Introduction to Tools of Lean Six Sigma 61

6.2 Lean Six Sigma Tools for Higher Education 62

6.2.1 Project Charter 62

6.2.2 Process Map 65

6.2.3 SIPOC 65

6.2.4 Value Stream Mapping 68

6.2.5 Cause and Effect Analysis (Fishbone
Diagram)

6.2.6 Root Cause Analysis $\quad 73$

6.2.7 Pareto Analysis $\quad 75$

6.2.8 Histogram $\quad 77$

6.2.9 Scatter Plot and Correlation Analysis $\quad 78$

6.2.10 Run Charts 80

6.2.11 Control Charts $\quad 82$

6.2.12 Standard Operating Procedures 85 
6.2.13 Waste Analysis 86

6.2.14 In-frame and out-frame Diagram 91

6.2.15 Failure Mode and Effect Analysis 91

6.2.16 Box Plot 94

6.2.17 Hypothesis Tests 96

6.3 Summary 98

References 98

Chapter 7 Perceived Non-value Added Activities in the Research Grant Application Process - Through a Lean Six Sigma Lens

Attracta Brennan and Mary Dempsey

7.1 Introduction 101

7.2 Key Drivers of the Research Grant Application Process 102

7.3 How Lean Six Sigma Can Support the Grant Application Performance

103

7.4 Challenges and Barriers within an Irish University's Grant Application Process 104

$\begin{array}{lll}7.5 & \text { Methodology } & 106\end{array}$

7.6 Key Findings 107

7.6.1 Online Survey Results $\quad 107$

7.6.2 Semi-structured Interviews $\quad 109$

7.7 Implications of the Study 116

7.8 Limitations of the Study 116

7.9 Recommendations and Directions for Further Research 116

7.10 Summary 119

References $\quad 121$

Chapter 8 Voice of the Customer in Higher Education 125

Scott P. Thomson and Jiju Antony

8.1 Introduction 125

8.1.1 What Is Voice of the Customer? 125

8.1.2 Why Does the Voice of the Customer
Matter?

8.2 Defining Customers 126

8.3 Customers in the Higher Education Sector $\quad 128$

8.3.1 Students 129 
8.3.2 Parents of Students $\quad 129$

8.3.3 Employers $\quad 130$

8.3.4 Government $\quad 130$

8.3.5 Alumni 130

8.3.6 Employees 131

8.4 VOC in Higher Education 131

8.4.1 The Current State of VOC in the Higher Education Sector 131

8.4.2 Why Should We Use VOC in Higher Education? 132

8.5 Stages to Develop a VOC Strategy 134

8.6 Case Study of VOC in Higher Education $\quad 138$

8.7 Summary 139

References 140

Chapter 9 A Lean Six Sigma Maturity Model for Higher Education Institutions

Stephen Anthony and Jiju Antony

9.1 Introduction

9.2 Research Methodology - Using Case Studies to Build a Model

9.2.1 Case Study Findings $\quad 142$

9.2.1.1 Case Study $1 \quad 142$

9.2.1.2 Case Study 2 142

9.2.1.3 Case Study 3

9.2.1.4 Case Study 4

9.3 Development of the Conceptual Model 145

9.4 Testing the Conceptual Maturity Model 148

9.5 Revised Lean Six Sigma Academic Maturity
Model

$\begin{array}{lll}9.6 & \text { Summary } & 149\end{array}$

References $\quad 159$

Chapter 10 Lean Six Sigma Roadmap for Implementation in Higher Education Sector

Vijaya Sunder M and Jiju Antony

10.1 Introduction 161

10.2 Awareness and Readiness 161 
10.3 Preparation

10.4 Initialization: Team Formation, Projects Identification and Prioritisation

164

10.5 Implementation: LSS Project Management and Programme Governance

10.6 Sustenance

10.7 Summary

References

\section{Chapter 11 Six Sigma and Big Data}

Chad Laux, Nimita Atal and John Springer

$\begin{array}{llc}\text { 11.1 } & \text { Introduction } & 171 \\ 11.2 & \text { The Data Revolution } & 171 \\ 11.3 & \text { What Is Big Data? } & 171 \\ 11.4 & \text { The Challenge of Big Data } & 172 \\ 11.5 & \text { Challenges of Six Sigma } & 173 \\ 11.6 & \text { The Six Sigma Big Data Proposition } & 173 \\ \text { 11.6.1 Define } & 176 \\ \text { 11.6.2 Measure } & 178 \\ \text { 11.6.3 Analyze } & 179 \\ \text { 11.6.4 Improve } & 179 \\ \text { 11.6.5 Control } & 180 \\ \text { 11.7 Summary } & 181 \\ \text { References } & 182\end{array}$

Chapter 12 Case Studies of LSS in Higher Education

12.1 Application of DMAIC in a HEI - An Improvement Project Case Study

12.1.1 Introduction

185

12.1.2 Application of DMAIC 185

12.1.2.1 Define Phase 186

12.1.2.2 Measure Phase $\quad 187$

12.1.2.3 Analyse $\quad 187$

12.1.2.4 Improve Phase $\quad 188$

12.1.2.5 Control Phase $\quad 190$

12.1.3 Key Outcomes and Lessons Learned 190

12.2 Application of LSS Methodology to Improve Service Process in Higher Education 
12.2.1 Introduction

192

12.2.2 DMAIC Methodology

196

12.2.2.1 Define Phase

196

12.2.2.2 Measure Phase

199

12.2.2.3 Analyse Phase

206

12.2.2.4 Improve Phase

12.2.2.5 Control Phase

213

12.3 Application of DMAIC in Improving Library Utilisation in a HEI: A Case Study

12.3.1 Introduction 215

12.3.2 DMAIC Methodology 215

12.3.2.1 Define Phase 216

12.3.2.2 Measure Phase

216

12.3.2.3 Analyse Phase

216

12.3.2.4 Improve Phase

218

12.3.2.5 Control Phase 
This page intentionally left blank 


\section{List of Figures}

\section{Chapter 1}

Figure 1.1. Process View of Lean Six Sigma.

\section{Chapter 3}

Figure 3.1. Steps of Systematic Literature Review Methodology.

\section{Chapter 6}

Figure 6.1. Lean Six Sigma Project Charter. 64

Figure 6.2. Process Mapping Symbols. 66

Figure 6.3. Sample Representation of Swim-lane Process Map. 66

Figure 6.4. Example of a SIPOC Analysis in a Higher Education Setting. $\quad 69$

$\begin{array}{lll}\text { Figure 6.5. Common Value Stream Mapping Symbols. } & 70\end{array}$

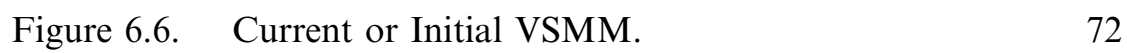

Figure 6.7. Fishbone Diagram to Illustrate the Causes of Student Dissatisfaction with the University Computer Center.

Figure 6.8. Root Cause Analysis Applied to a Postgraduate Research Application Process. $\quad 76$

Figure 6.9. Pareto Chart of Student Failures in Subjects. $\quad 77$

$\begin{array}{ll}\text { Figure 6.10. Histogram of Marks from a Postgraduate Course. } & 79\end{array}$

Figure 6.11. Different Scenarios for Relationships between Two Variables on a Scatter Plot. $\quad 80$

Figure 6.12. Example of a Scatter Plot. 81 
Figure 6.13. Example of a Run Chart in a Higher Education Setting.

Figure 6.14. Example of an Individual Control Chart. 83

Figure 6.15. An Example of an Individual Control Chart. 85

Figure 6.16. Standard Operating Procedures for Library Book Search Process.

Figure 6.17. Eight Forms of Waste in a Higher Education Sector.

Figure 6.18. Failure Modes and Effect Analysis.

Figure 6.19. Revised Failure Modes and Effect Analysis after Remedial Measures Taken.

Figure 6.20. Example of a Box Plot.

\section{Chapter 7}

Figure 7.1. Research Grant Application Support Tool.

\section{Chapter 8}

Figure 8.1. High-level Customer Definition Tool for a Higher Education Institution.

Figure 8.2. Student-customer Definition Tool for a Higher Education Institution.

\section{Chapter 9}

Figure 9.1. A Lean Six Sigma Maturity Model for Academic Leaders and Institutions.

Figure 9.2. The Final Maturity Model for Leaders Implementing Six Sigma in Academic Institutions.

\section{Chapter 10}

Figure 10.1. LSS Implementation Roadmap for Higher Education Institutions.

\section{Chapter 11}

Figure 11.1. Six Sigma Big Data Model.

\section{Chapter 12}

Figure 12.1. Input-Process-Output (IPO) Transcripts Process. 186

Figure 12.2. Fishbone Analysis. 188 
Figure 12.3. Quality Improvements.

Figure 12.4. Box Plot - Cycle Time of Transcript Ordering Process.

Figure 12.5. Gemba - 'before' and 'after'.

Figure 12.6. Vision of Sponsored Program Services Office (SPS Website, 2018).

Figure 12.7. Pre-award Proposal Submission Service Process Flow Chart.

Figure 12.8. Hierarchy of Pre-award SPS Office. 197

Figure 12.9. SIPOC Model of SPS Service. 200

Figure 12.10. Number of Proposals in the Pre-award Area (2015-2016).

Figure 12.11. Amount of Proposals in the Pre-award Area (2015-2016).

Figure 12.12. Distribution of Prior to Deadlines.

Figure 12.13. Time Series Plot of Late Submission Proposal (2015-2016).

203

Figure 12.14. Distribution of PL Lead Time. 203

Figure 12.15. Descriptive Statistics for Proposal Effort Score. 204

Figure 12.16. Process Mapping for Proposal Submission Process in Pre-award Office.

Figure 12.17. Descriptive Statistics Report of Processing Time. 205

Figure 12.18. Categories 1-4 of Proposal Submission Prior to Deadline in Terms of Different Grant Types.

Figure 12.19. Cumulative Percentage of Prior to Deadline Timeline.

Figure 12.20. Fishbone Diagram for Imbalanced Workload. 209

Figure 12.21. Pre-Award Service Timeline (SPS Website, 2018). 212

Figure 12.22. Failure Mode of Effect Analysis (FMEA). 213

Figure 12.23. Project Charter. 217

Figure 12.24. Pareto Chart of Vital Few Causes. 218

Figure 12.25. Box Plot of Project Metric before and after the Project. 
This page intentionally left blank 


\section{List of Tables}

\section{Chapter 6}

Table 6.1. Data for Comparing the Average Marks of Students.

\section{Chapter 7}

Table 7.1. Semi-structured Interviews.

Table 7.2. Recommendations.

\section{Chapter 8}

Table 8.1. VOC Research vs Management Perceptions of Student Dropout Drivers.

\section{Chapter 9}

Table 9.1. The Positions of the Interviewees from Case Study Organisations.

Table 9.2. Linking the Evidence to the Themes.

Table 9.3. Conceptual Model Testers and Reviewers.

Table 9.4. Level 0 Characteristics and Descriptors.

Table 9.5. Level 1 Characteristics and Descriptors.

Table 9.6. Level 2 Characteristics and Descriptors.

Table 9.7. Level 3 Characteristics and Descriptors. 155

Table 9.8. Level 4 Characteristics and Descriptors. 156

\section{Chapter 11}

Table 11.1. Comparison of Six Sigma and Big Data Principles. 175 
$\boldsymbol{x} \boldsymbol{x}$ List of Tables

\section{Chapter 12}

Table 12.1. Opportunities for Improvement. 189

Table 12.2. Project Charter. 193

Table 12.3. Categories 1 to 4 of Proposal Submission Prior to Deadline in Terms of Different Grant Types. 198

Table 12.4. Regression Analysis for Proposal Effort Score and PI Lead Time with Final Submission Prior to Grant Deadline. 208

Table 12.5. Identified Lean Wastes in Percentage of Proposals. 210

Table 12.6. Percentage Reduction in Seven Typical Lean Wastes. 


\section{List of Contributors}

Dr Stephen Anthony

Prof. Jiju Antony

Ms Nimita Atal

Dr Attracta Brennan

Dr Elizabeth A. Cudney

Mrs Mary Dempsey

Dr Sandy L. Furterer

Mr Joe Healy

Dr Roger Hoerl

Dr Chad Laux

Dr Na Li

Mr John McNulty

Mr Tom Murphy

Ms Helen O'Donovan

Mr Ronan O’Dubhghaill

Mr Seamus O'Reilly

Dr Ronald Snee

Dr John Springer

Prof. Vijaya Sunder M

Mr Scott P. Thomson
Heriot-Watt University, UK

Heriot-Watt University, UK

Purdue University, USA

National University of Ireland, Ireland

Maryville University of Saint Louis, USA

National University of Ireland, Ireland

University of Dayton, USA

University College Cork, Ireland

Union College, USA

Purdue University, USA

Purdue University, USA

University College Cork, Ireland

University College Cork, Ireland

University College Cork, Ireland

University College Cork, Ireland

University College Cork, Ireland

Snee Associates, USA

Purdue University, USA

Indian School of Business, India

Heriot-Watt University, UK 
This page intentionally left blank 


\section{Preface}

Businesses today are always on the lookout for ways to improve their bottom line by systematically eliminating waste from business processes as well as reducing unnecessary or undesirable variation in business processes which result in defects, errors or even failures leading to customer dissatisfaction. Lean Six Sigma (LSS) has become predominant in many fields. It is among the most common continuous improvement methodologies today. And while other industries, namely, manufacturing, service and some public healthcare services have adopted LSS to improve operations and focus on efficiency and effectiveness, Higher Education Institutions (HEIs) have largely been impervious to such continuous improvement efforts.

HEIs have been a cornerstone in educating society's leaders, an incubator for advanced technologies and an accelerator for economic development. The situation within the Higher Education (HE) sector is very similar to that of firms within the manufacturing and service industry - facing fierce competition, limited budget availability, government funding slashed, and students adopting a consumer approach to their learning. There are a few books on Lean in Higher Education, but the editor and contributors of this book would like to highlight the point to readers that both Lean and Six Sigma or even its integrated approach (Lean Six Sigma) can equally be applied to improve the efficiency and effectiveness of business processes in the HE sector. Moreover, only some problems can be tackled using the Lean approach in our view and hence the integrated approach can be more beneficial for tackling problems where variation is the primary issue (e.g. variation in turnaround times, variation in recruitment times of research staff for funded projects, etc.).

Higher education has become a competitive enterprise, with the characteristics of an organization that must compete for scarcity, as students replace funding from state resources. As universities compete for status and rank, the competitive nature can contribute toward a decline in the sense of academic mission, community and values. The ability to maintain the academy requires effort from a variety of resources, disciplines and ideas as the commercialization of higher education strains the social mission. LSS as a powerful Operational Excellence strategy is one contributing effort that can impact these trends of massification of the academy, and we hope the literature presented in this work will support a concerted effort to respond to the concern for quality in Higher Education.

This book is a collection of articles written by a number of contributors from three continents: Asia, Europe and North America. The book is a carefully edited 
work by an academic and a practitioner of Operational Excellence based in the Higher Education sector. The book encompasses state-of-the-art literature review on LSS in HE sector, case studies of LSS in HE, tools of LSS which can be used in HE, challenges in the implementation of LSS in the HE setting, significance of Voice of the Customer, LSS Maturity Model for HE and emerging trends in the area. This book will benefit students, researchers, professional staff who would like to engage in process improvement projects in HE environments, and academics who would like to understand the concepts of Lean Six Sigma, as well as the challenges and barriers in the implementation and sustenance of this powerful Operational Excellence methodology. I firmly believe that the applications of LSS in HE will continue to grow over the years and this book is very timely. The book can be a great resource for training staff members in the HE sector or for selfstudy to understand the challenges in the implementation. Moreover, it provides the most powerful tools of LSS which can be used in Higher Education setting for problem-solving scenarios. Finally, I would like to thank all readers who are using this book for the LSS journey, and we wish the very best of luck with your endeavours. 


\section{Acknowledgements}

I am deeply indebted to a number of people who, in essence, have made this book what it is today. First, and foremost, I would like to thank a number of contributors who have devoted their time in writing a chapter or chapters for the book. I am most grateful to the reviewers of the proposal and sample chapters for their invaluable suggestions that guided the preparation of this book. It is my sincere hope that by reading this edited book, you will find something new which will challenge your personal thoughts in a new way. Your suggestions and constructive feedback regarding the contents of the book will be taken into account, and I will do my best to overcome any shortcoming in the future editions of this book. Finally, I would like to express my sincere thanks to my family for their encouragement and patience as the book stole countless hours away from family activities. Finally, I take this opportunity to thank Emerald Publishing for their incessant support and forbearance during the course of the project. 